\title{
IGF2BP2 Promotes the Proliferation, Invasion and Migration of Esophageal Carcinoma Cells via Activation of the PI3K/AKT/EMT Signaling Pathway
}

\section{Wenbin Shu}

Fifth Affiliated Hospital of Sun Yat-sen University https://orcid.org/0000-0002-7426-5541

\section{YuJing Lin}

Fifth Affiliated Hospital of Sun Yat-sen University

\section{Yan Yan}

Fifth Affiliated Hospital of Sun Yat-sen University

YaoHui Sun

Fifth Affiliated Hospital of Sun Yat-sen University

\section{XiangWen Wu}

Fifth Affiliated Hospital of Sun Yat-sen University

Qingdong Cao ( $\triangle$ caoqingdong1988@126.com )

Fifth Affiliated Hospital of Sun Yat-sen University

\section{Research}

Keywords: Human insulin-like growth factor 2-binding protein 2 (IGF2BP2), esophageal squamous cell carcinoma (ESCC), invasion, migration, epithelial-mesenchymal transition (EMT)

Posted Date: July 15th, 2021

DOl: https://doi.org/10.21203/rs.3.rs-711778/v1

License: (c) (1) This work is licensed under a Creative Commons Attribution 4.0 International License. Read Full License 


\section{Abstract}

\section{Background}

Insulin-like growth factor 2 (IGF2) mRNA-binding protein 2 (IGF2BP2), as a m6A "reader", is known to be an oncogene, and its expression is elevated in multiple tumors. However, the role of IGF2PB2 in esophageal squamous cell carcinoma (ESCC) is still unclear.

\section{Methods}

This study aims to investigate the role of IGF2PB2 expression in ESCC proliferation, invasion and migration as well as the possible mechanism. IGF2BP2 expression was found to be elevated in ESCC tissues by qRT-PCR, western blotting, and immunohistochemical (IHC) staining.

\section{Results}

Knocking down IGF2BP2 expression prevented the proliferation, invasion, migration and epithelialmesenchymal transition (EMT) of KYSE450 and TE1 cells. Knocking out IGF2BP2 reduced tumorigenesis in vivo. Overexpression of IGF2BP2 was performed, and it was proven that IGF2BP2 had an oncogenic effect in KYSE450 and TE1 cells. Moreover, LY294002, a highly selective inhibitor of PI3K, reversed the effect of IGF2BP2 overexpression on EMT processes. All these results show that the effects of IGF2BP2 on oncogenesis and EMT were clearly exerted via the PI3K/AKT signaling pathway.

\section{Conclusions}

In conclusion, this study demonstrates that the oncogenic function of IGF2BP2 is mediated by the $\mathrm{PI3K} / \mathrm{AKT}$ signaling pathway and is related to EMT in ESCC. In addition, IGF2BP2 can serve as a diagnostic and oncotherapeutic marker in further studies.

\section{Introduction}

Esophageal squamous cell carcinoma is a common malignant tumor of the digestive system.

Approximately $95 \%$ of patients with esophageal cancer in Asia have squamous cell carcinoma ${ }^{[1]}$. Due to a lack of research advances, effective discovery diagnosis markers, and sound treatments, as well as tumor metastasis and recurrence, the five-year survival rate of esophageal cancer patients is poor ${ }^{[2-4]}$. Therefore, there is an urgent need to discover new and effective biomarkers that correlate with proliferation, invasion and migration. Furthermore, this paper holds that it is very important to determine the mechanisms associated with these key markers for the early discovery, diagnosis, and treatments of ESCC.

In recent research, IGF2BP2 was found not only to be an RNA-binding protein (RBP) but also to serves as a m6A "reader" to stabilize mRNA, and control translation and alternative splicing ${ }^{[5-7]}$. Accumulating of evidence indicates that IGF2BP2 plays an important functional role in various kinds of tumors, such as 
breast cancer, colorectal cancer, hepatocellular carcinoma, and gastric cancer. One of the main functions of IGF2BP2 is the regulation of tumorigiensis, invasion, and migration ${ }^{[8-10]}$. IGF2BP2 belongs to a conserved family of mRNA-binding proteins (RBP). IGF2BP2 is composed of two RNA recognition motif (RRM) domains and four $\mathrm{K}$ homology $(\mathrm{KH})$ domains. IGF2BP2 recognizes thousands of target mRNAs,

but, which targets are recognized by IGF2BP2 in ESCC remains unclear ${ }^{[11-12]}$. IGF2BP2 rs1470579 A > C polymorphisms are associated with a decreasing risk of $E G J A^{[13]}$, but it has been found that the expression of IGF2BP2 is notably increased in esophageal squamous carcinoma tissues and correlates with clinical characteristics ${ }^{[14]}$. It has been reported that upregulating IGF2BP2 expression can promote pancreatic cancer cell growth by activating the PI3K/AKT signaling pathway in vitro and in vivo ${ }^{[15]}$. IGF2BP2 is also highly expressed and promotes in GBM progression by activating the IGF2/PI3K/AKT signaling pathway ${ }^{[16]}$. However, the effect of IGF2BP2 on ESCC and the underlying mechanism are unclear. This paper hypothesizes that IGF2BP2 activates the PI3K/AKT signaling pathway to induce the proliferation, migration, invasion and EMT of ESCC.

\section{Materials And Methods}

\section{Clinical patient samples}

ESCC tissues and normal esophageal tissues were collected from The Fifth Affiliated Hospital, Sun Yatsen University. All the positive samples were esophageal squamous cell carcinoma, as diagnosed by pathologists who confirmed the diagnosis, and none of the patients received chemoradiotherapy or targeted biotherapy before the operation. In this study, the patients provided written consent, and the collection of patient specimens was approved by the ethics committee.

\section{Cell culture condition}

The human esophageal cancer cell lines KYSE450, and TE1 were obtained from the Institute of Basic Medical Science, Chinese Academy of Medical Sciences. The cell lines were cultured in Roswell Park Memorial Institute (RPMI) 1640 supplemented with 10\% fetal bovine serum (FBS) and 1\% penicillinstreptomycin. The cell lines were cultured in a humidified $5 \% \mathrm{CO}_{2}$ atmosphere at $37^{\circ} \mathrm{C}$.

\section{Immunohistochemical staining}

Immunohistochemical staining for IGF2BP2 was performed. A rabbit polyclonal IGF2BP2 antibody (1:400; Cell Signaling Technology, MA, USA) was used to detect the IGF2BP2 protein levels in the cytoplasm. The cytoplasmatic staining intensity was evaluated by two independent investigators who were unaware of the clinical parameter values. If the replicates of the same tumor differed in staining intensity, then median values were used for further analysis.

\section{Total RNA extraction and RT-qPCR}


Total RNA was extracted from KYSE450, and TE1 cells, and tissues using TRIzol (Invitrogen) according to the manufacturer's instructions. Two microliters of total RNA was reversed into cDNA by using PrimeScript ${ }^{\text {TM }}$ RT Master Mix (Perfect Real Time) (Takara Bio). A SYBR Green PCR Kit (Invitrogen) was used to determine the levels of the RNA transcripts with the Bio-Rad CFX96 optical real-time PCR system (Bio-Rad, USA). IGF2BP2 expression was normalized to $\beta$-actin expression and calculated using the comparative CT (2- $\triangle \triangle C T)$ method. The primers used were IGF2BP2 forward 5'-

AGCTAAGCGGGCATCAGTTTG-3' and reverse 5'-CCGCAGCGGGAAATCAATCT-3' and $\beta$-actin forward 5 'CCAACCGCGAGAAGATGA-3' and reverse 5'-TCCATCACGATGCCAGTG-3'. All the samples were tested in triplicate.

\section{Western blotting and antibodies}

KYSE450 and TE1 cells were washed three times with cold PBS and incubated with RIPA lysis buffer (Beyotime Biotechnology, Shanghai, China) and protease inhibitors and phosphatase inhibitors cocktails for $30 \mathrm{~min}$ on ice. The lysates were collected in an EP tube and centrifuged at maximum speed for $15 \mathrm{~min}$. The supernatant was placed into a new EP tube, and the protein concentration was detected. Then, the proteins were boiled with SDS/PAGE sample buffer (50 mM Tris-HCI [pH 6.8], 2\% SDS, $0.1 \%$ bromophenol blue, $10 \%$ glycerol, and $1 \mathrm{mM}$ dithiothreitol) for $10 \mathrm{~min}$, and the proteins were separated by SDS/PAGE. The proteins were transferred to nitrocellulose filter membranes (Roche, USA), blocked with $5 \%$ nonfat milk in TBST buffer for $1 \mathrm{~h}$, and then incubated with IGF2BP2 antibodies at $4^{\circ} \mathrm{C}$ overnight. After washing the NC membranes for three times and incubating with HRP-conjugated secondary antibodies (Cell Signaling Technology, MA, USA) at $37^{\circ} \mathrm{C}$ for $1 \mathrm{~h}$, we used Gension ${ }^{\text {TM }}$ Enhanced ECL (solution A: solution B $=1: 1$ ) (Gension, Guangzhou, China) to detect the protein bands, and a ChemiDocXRS+imaging system (Bio-Rad, USA) was used to image the protein bands. The gray values of the IGF2BP2 and $\beta$-actin bands were detected by using ImageJ software (National Institutes of Health, USA). The antibodies were used included: anti-IGF2BP2 (1:1000, Cell Signaling Technology), anti- $\beta$-actin (1:5000, Cell Signaling Technology), anti-Snail (1:1000, Cell Signaling Technology), anti-E-cadherin (1:1000, Cell Signaling Technology), anti- $\beta$-Catenin (1:1000, Cell Signaling Technology), anti-PI3K (1:1000, Cell Signaling Technology), anti-AKT (1:1000, Cell Signaling Technology), and anti-p-AKT (1:1000, Cell Signaling Technology).

\section{Wound healing assay}

A total of $6 \times 10^{5}$ cells were inoculated in 6 -well plates. When the cells reached $80 \%$ confluence, 5 stripes

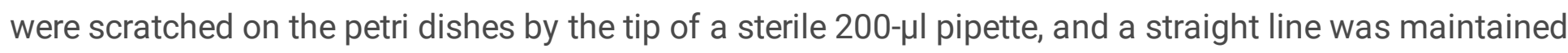
to simulated a wound. PBS was used to wash the wells 3 times to remove the unmattached cells. Serumfree medium was added, and the plates were incubated in a humidified $5 \% \mathrm{CO}_{2}$ atmosphere at $37^{\circ} \mathrm{C}$. Photographs were taken at $0 \mathrm{~h}$ and $36 \mathrm{~h}$ injury to observe the healing of the wound.

\section{Cell invasion and migration assays}


We diluted Matrigel to $200 \mu \mathrm{g} / \mathrm{ml}$ with serum-free RPMl 1640 medium, and $100 \mu$ l diluted Matrigel was used to cover 24 -well plates, which were incubated at $37^{\circ} \mathrm{C}$ for $2 \mathrm{~h}$. The cells were placed in the culture plate and a $600 \mu \mathrm{l}$ serum-free medium was added to the lower chamber. The serum-free medium was allowed to incubate at room temperature for $30 \mathrm{~min}$ to rehydrate the Matrigel. Before preparing the cell suspension, the cells were starved for $12 \mathrm{~h}$. The cells were digested, and centrifuged, and the culture medium was discarded, Then, the cells were washed twice with PBS and resuspended in serum-free medium. The cell density was adjusted to $5 \times 10^{4} /$ cells well; $200 \mu$ l of the cell suspension was added to the Transwell chamber, and $600 \mu \mathrm{l}$ RPMI 1640 medium with 10\% FBS was added to the lower chamber of the 24-well plate. Bubbles between the lower chambers and the upper chambers were eliminated. After conventional culture for $24 \mathrm{~h}$, the unmigrated cells were removed from the upper surface of the membrane with cotton swabs, and the migrated cells were fixed in formaldehyde, and stained with crystal violet, Then the cells were counted.

\section{Cell proliferation assay}

KYSE450 and TE1 cells were successfully cultured in 6-well plates and then transferred with sh-IGF2BP21, sh-IGF2BP2-2, and NC for $24 \mathrm{~h}$. The KYSE450 and TE1 cell lines were seeded in 96-well plates $\left(1 \times 10^{4} \mathrm{cells} /\right.$ well) and cultured for $24 \mathrm{~h}$ at $37^{\circ} \mathrm{C}$ with $5 \%$ CO2. A CCK-8 assay(Meilunbio Da Lian China) was used to determine cell proliferation. Every 96-well plate was washed twice with PBS, and then, $100 \mu \mathrm{l}$ suspension medium ( $90 \mu \mathrm{l}$ medium with $10 \%$ FBS and $10 \mu \mathrm{l} \mathrm{CCK}-8)$ was added and cultured routinely for $2 \mathrm{~h}$, The OD value was measured at $450 \mathrm{~nm}$ on an enzyme plate meter. Three independent experiments were performed.

\section{Plasmids and lentiviral shRNA infection}

The sequence of the interfering RNAs were as follows: sh-IGF2BP2-1 TTTCAGTTTCCCAAAGATCCG; shIGF2BP2-2 GCTGTTAACCAACAAGCCAAT; NC GTTCTCCCGAACGTGTCACGT (GenePharma, China). The sequences for IGF2BP2 overexpression are shown in Table $\mathrm{S} 1$ of the additional file 1. The sh-IGF2BP1,2 was synthesized, annealed, and cloned into the pGDV6/GFP/Neo vector to lentivirus-mediated interference (Shanghai Jikai Gene Medicine Technology Co., Ltd, China).

\section{In vivo experimental study}

After discussion and approval by the Animal Ethics Committee of the Fifth Affiliated Hospital of Sun Yatsen University, we were allowed to purchase male 4-week-old BALB/C nude mice from Guangdong Animal Center (Guangzhou, China), and we performed all the animal experiments following the Animal Care Ethics Guidelines (000178). A total of $2 \times 10^{6} \mathrm{KYSE} 450$ esophageal carcinoma cells were subcutaneously injected into the right hindquarters subcutaneous of nude mice to form subcutaneous tumors. Vernier calipers were used to measure the length and diameter of the tumor to calculate the size and volume of the tumor. An in situ xenograft model was successfully constructed, and the method for establish this model was as follows Nude mice were injected with sodium pentobarbital $(60 \mathrm{mg} / \mathrm{kg})$ in the enterocoelia to maintain the anesthetic effect, and then we opened the enterocoelia of the mice at the midline of the 
abdomen. Then, the gastric segment was identified and pulled down to expose the segment of the esophagus in the abdomen ${ }^{[16-17]}$. Stably transfected KYSE-450-luciferase cells were suspended in PBS (Corning, Tewkesbury, MA, USA), and $50 \mu$ tumor cell suspension was injected into the esophagus. Notably, there was no extravasation of the tumor cell suspension and no injection into the esophageal lumen. The edematous appearance of the esophagus indicated that the mice were successfully injected. The enterocoelia was closed, and the skin was sutured.

\section{Statistical analysis}

In this study, all the experiments were performed repeatedly for three times. All the data are summarized expressed as the mean \pm SD. The two groups were evaluated by using a two-tailed Student's t-test and variance. SPSS (version 20.0 (Chicago, IL, USA) ) and GraphPad Prism (version 8.0 GraphPad Software, La Jolla, USA) was used for statistical analysis. When the P-value was $<0.05$, the results were considered to be significally in statistics.

\section{Results}

\section{IGF2BP2 is overexpressed in esophageal cancer}

To investigate the expression and the potential value of IGF2BP2 in ESCC, we first used the GEPIA (http://gepia.cancer-pku.cn/) database and showed that 182 esophageal cancer tissues had high expression of IGF2BP2 than 286 normal tissues (Fig. 1a; $P<0.05$ ). Then we found that the mRNA expression of IGF2BP2 in esophageal cancer tissues was significantly higher than that in normal tissues, as determined by RT-qPCR (Fig. 1b). The protein expression in $82.6 \%$ of esophageal cancer tissues was higher than that in normal tissues, as determined by western blotting (Fig. 1d). The clinical information of the patients is listed in Table 1. All 178 ESCC patients were recruited from The Fifth Affiliated Hospital, Sun Yat-sen University, between January 2016 and December 2020. The expression of IGF2BP2 in the esophageal cancer tissues and normal tissues was showed by using IHC staining (Fig. 1C). The expression level of IGF2BP2 and clinicopathological features of patients were analyzed. No significant difference was observed between the expression of IGF2BP2 and age, sex, or tumor size. However, the results showed that the expression of IGF2BP2 was associated with invasion depth $(P=0.001)$, lymph node status $(P=0.036)$ and TNM stage $(P=0.021)$. Therefore, the results suggest that IGF2BP2 is overexpressed in ESCC and may promote ESCC progression. 
Table 1

The findings between IGF2BP2 expression and clinicopathological characteristics in 178 ESCC patients.

\begin{tabular}{|c|c|c|c|c|}
\hline Variables & No. (\%) & IGF2BP2 low & IGF2BP2 high & $P$ value \\
\hline Total cases & 178 & $11(6.2 \%)$ & $167(93.8 \%)$ & \\
\hline \multicolumn{5}{|l|}{ Age $(N=178)$} \\
\hline$<65$ & 108 & 5 & 103 & \multirow[t]{2}{*}{$P=0.286$} \\
\hline$\geq 65$ & 70 & 6 & 64 & \\
\hline \multicolumn{5}{|c|}{ Gender $(N=178)$} \\
\hline Male & 135 & 20 & 115 & \multirow[t]{2}{*}{$P=0.052$} \\
\hline Female & 43 & 12 & 31 & \\
\hline \multicolumn{5}{|c|}{ Tumor size $\left(\mathrm{cm}^{3}\right)(\mathrm{N}=58)$} \\
\hline$<5.4$ & 39 & 9 & 30 & \multirow[t]{2}{*}{$P=0.092$} \\
\hline$\geq 5.4$ & 19 & 1 & 18 & \\
\hline \multicolumn{5}{|c|}{ Tumor invasive depth $(\mathrm{N}=58)$} \\
\hline $1-2$ & 14 & 6 & 8 & \multirow[t]{2}{*}{$P=0.001$} \\
\hline $3-4$ & 44 & 3 & 41 & \\
\hline \multicolumn{5}{|c|}{ Lymph node status $(\mathrm{N}=58)$} \\
\hline$<1$ & 33 & 1 & 32 & \multirow[t]{2}{*}{$P=0.036$} \\
\hline$\geq 1$ & 25 & 5 & 20 & \\
\hline \multicolumn{5}{|c|}{ TNM stage $(\mathrm{N}=58)$} \\
\hline$|-I|$ & 35 & 1 & 34 & \multirow[t]{2}{*}{$P=0.021$} \\
\hline III-IV & 23 & 5 & 18 & \\
\hline \multicolumn{5}{|c|}{ According to the 8th Edition of the AJCC Cancer Staging Manual. } \\
\hline \multicolumn{5}{|c|}{ Patient's tumor size was divided into two groups based on the mean value. } \\
\hline
\end{tabular}

Downregulation of IGF2BP2 expression suppressed the proliferation, migration and invasion of ESCC cells 
To illustrate the impact of the downregulation of IGF2BP2 expression in ESCC cells, The expression of IGF2BP2 was knocked down in KYSE450 and TE1 cells by using sh-IGF2BP2-1, sh-IGF2BP2-2, and NC. The western blotting assay confirmed that the expression of IGF2BP2 in these groups was lower than the control group (Fig. 2a). we performed a CCK8 assay to evaluate cell proliferation and found that downregulating the expression of IGF2BP2 suppressed cell proliferation (Fig. 2b). The migration of KYSE450 and TE1 cells was verified using Transwell migration assays and wound healing assays. We found downregulated IGF2BP2 expression inhibits the migration ability of the KYSE450 and TE1 cell lines. Transwell invasion assays demonstrated that the invasion abilities of the KYSE450 and TE1 cells were decreased in the sh-IGF2BP2-1 and sh-IGF2BP2-2 groups compared to the normal control group (Fig. 2c-d). All the results indicate that IGF2BP2 plays an oncogenic role by facilitating the proliferation, migration and invasion of ESCC cells.

\section{Overexpression of IGF2BP2 promotes proliferation, migration and invasion of ESCC cells}

To explore the functional role of IGF2BP2 in the proliferation, migration and invasion associated with ESCC progression. we overexpressed IGF2BP2 in the KYSE450 and TE1 cell lines by using the IGF2BP2overexpressing plasmid. Both the KYSE450 and TE1 cell lines were stably expressed IGF2BP2, which was validated by western blotting (Fig. 3a). CCK-8 assays showed that the overexpression of IGF2BP2 accelerated the proliferation of KYSE450 and TE1 (Fig. 3b). The role of IGF2BP2 in the migration and invasion of ESCC cells was assessed by Transwell assays, which showed that the cell migration and invasion abilities were significantly accelerated in the IGF2BP2-overexpressing cells compared to the control cells (Fig. 3C). The migration of ESCC cells was promoted by the overexpression of IGF2BP2 (Fig. 3d). All the findings indicate that intracellular IGF2BP2 plays oncogenic roles by promoting the proliferation, migration and invasion of ESCC cells.

\section{IGF2BP2 regulatts the epithelial-mesenchymal transition (EMT) in ESCC cells}

The downregulation and overexpression of IGF2BP2 affected the proliferation, invasion, and metastasis functions of the KYSE450 and TE1 cell lines. EMT is a crucial biological process by which epithelial malignant tumor cells acquire migration and invasion abilities ${ }^{[18]}$. To verify that the IGF2BP2 might be involved in the process of EMT and to assess the effect of IGF2BP2 on the migration and invasion of KYSE450 and TE1 cells. we evaluated the expression levels of EMT markers by western blotting. ShIGF2BP2-1, and sh-IGF2BP2-2 upregulated the protein expression of E-cadherin and reduced the protein expression of snail, and $\beta$-catenin in KYSE450 and TE1 cells (Fig. 4b). In contrast, overexpressed IGF2BP2 increased snail, and $\beta$-catenin expression and reduced E-cadherin expression (Fig. 4a). These results confirm that IGF2BP2 could promoted the EMT of esophageal tumor cells.

The effect of IGF2BP2 on EMT depends on the activation of the PI3K/AKT signaling pathway. Studies have shown that the PI3K/AKT signaling pathway can promote the progression of EMT and thus affect the invasion and metastasis of tumor cells. Other studies have shown that IGF2BP2 expression is

correlated with the PI3K/AKT signaling pathway ${ }^{[19-21]}$. Therefore, the KYSE450 and TE1 cells were transfected with sh-IGF2BP2-1, sh-IGF2BP2-2 and overexpression plasmids. We measured the protein 
expression levels of PI3K, AKT and p-AKT. Our results showed that the PI3K, and p-AKT levels,but not the AKT protein levels, were significantly reduced after silencing of IGF2BP2 (Fig. 4b). Similarly, there was no significant change in the protein expression level of AKT. The PI3K and p-AKT levels were increased in KYSE450 and TE1 after overexpression of IGF2BP2 (Fig. 4a). To further demonstrate the effect of IGF2BP2 that promoted proliferation, migration, invasion in the KYSE450 and TE1 cells, we treated IGF2BP2-overexpressing KYSE450 and TE1 cells with the PI3K inhibitor LY294002. Our results showed that the expression levels of PI3K, and p-AKT significantly decreased in the IGF2BP2-overexpressing KYSE450 and TE1 cells (Fig. 4c). The results were accompanied by the downregulation of Vimentin and Snail expression and the upregulation of E-cadherin expression in IGF2BP2-overexpressing cells (Fig. 4c). Furthermore, we assessed the proliferation, migration and invasion ability of IGF2BP2-overexpressing KYSE450 and TE1 cells after treatment with LY294002. The migration, and invasion abilities of IGF2BP2overexpressing KYSE450 and TE1 cells were reversed by the PI3K inhibitor LY294002 (Fig. 4d-e).

\section{Downregulation of IGF2BP2 suppress tumor growth In vivo}

We demonstrate that IGF2BP2 promotes esophageal cancer cell proliferation, migration, and invasion and promotes EMT through the PI3K/AKT signaling pathway. Next, we explored the role of IGF2BP2 in vivo. After transfection of KYSE450 cells with lentivirus expressing sh-IGF2BP2-1,2 and sh-NC. we established a model of subcutaneous xenografts in the right lower limb of nude mice. The results showed that the downregulation of IGF2BP2 expression suppressed tumor growth in this model (Fig. 5a-C).

\section{Discussion}

The poor prognosis of esophageal cancer is due to the strong proliferation, invasion and metastasis abilities of esophageal cancer cells ${ }^{[22-23]}$. It is significantly important to identify the genes involved in proliferation, migration and invasion for the accurate diagnosis and development of the therapeutic strategies for esophageal cancer ${ }^{[24-25]}$. It was discovered that the copy number of IGF2BP2 in tumor tissues was higher than that in adjacent normal tissues. IGF2BP2 expression promotes HCC cell proliferation in vitro and in vivo ${ }^{[27]}$. IGF2BP2 may play an oncogenic role in promoting tumor growth by inhibiting the tumor immune response reported in $\mathrm{SCCHN}^{[28]}$. In addition, the overexpression of IGF2BP2 can partially reverse the invasion and migration abilities of cells overexpressing miR-138 ${ }^{[29]}$. IGF2BP2 KD reversed the decreased cell adhesion and the increased invasion of CCN6 KD HME cells compared to controls $^{[30]}$. All studies have shown that IGF2BP2 promotes cancer in multiple studies ${ }^{[5,7,26]}$. However, the oncogenic role of IGF2BP2 in ESCC is still unclear.

In this study, the IGF2BP2 protein and mRNA levels were overexpressed in ESCC tissue and the levels of IGF2BP2 were positively in correlated with invasion depth, TNM stage and lymphatic metastasis. The results show that IGF2BP2 plays an oncogenic role when IGF2BP2 expression is downregulated in vitro and in vivo and IGF2BP2 is overexpressed in vitro. Moreover, downregulated IGF2BP2 protein expression helps to reduce the proliferation, migration and invasion of ESCC cells. In contrast, upregulated IGF2BP2 expression leads to an increase in the proliferation, migration and invasion of ESCC cells. 
EMT promotes the invasion and metastasis of tumors ${ }^{[31-32]}$. A feasible way to assess the degree to which tumor epithelial cells transform into mesenchymal cells is to detect theexpression of EMT markers, such as E-cadherin, Snail and $\beta$-catenin. This approach also allows the evaluation of the invasion and metastasis abilities of tumors ${ }^{[33-35]}$. Our results demonstrate that downregulating the expression of IGF2BP2 can inhibit the migration and invasion abilities of ESCC cells and that the expression of Ecadherin, $\beta$-catenin and snail is decreased. Overexpressing IGF2BP2 enhances the migration and invasion abilities of ESCC cells, and the expression of E-cadherin, $\beta$-catenin and snail is increase which suggests that IGF2BP2 initiates EMT to mediated the migration and invasion.

According to studies, many genes can regulate EMT by activating the PI3K/AKT signaling pathway which will promote tumor migration and invasion ${ }^{[36-37]}$. Overexpression of IGF2BP2 promotes cancer proliferation by activating the PI3K/AKT signaling pathway and is correlated with poor survival in pancreatic cancer ${ }^{[38-39]}$. Studies show that IGF2BP2 regulates cell migration, invasion and EMT in glioblastoma multiforme cells and activates the PI3K/AKT signaling pathway ${ }^{[40]}$. We performed experiments to verify whether the PI3K/AKT signaling pathway is activated by IGF2BP2. Our data show that p-AKT and EMT are decreased by the PI3K inhibitor LY294002 in IGF2BP2-overexpressing cells and control cells. Indicating that the IGF2BP2 promotes EMT via the PI3K/AKT signaling pathway. We found that not all LY294002 could reversed the activation of PI3K/AKT signaling pathway by overexpression of IGF2BP2, which indicated that IGF2BP2 activated the PI3K/AKT signaling pathway, but to a moderate degree (data not shown). Alternatively IGF2BP2 may be involved in the activation of other signaling pathways that weaken the effect of LY294002 on the PI3K/AKT signaling pathway. This study is limited by omission of other inhibitors of the PI3K/AKT pathway. In addition, we could not analyze the survival data due to the lack of follow-up information on patients. Moreover, we have not successfully established a nude mouse lung metastasis model with KYSE450 and TE1 esophageal cancer cell lines.

\section{Conclusions}

In conclusion, we indicate that IGF2BP2 plays an oncogenic role in ESCC. Overexpression of IGF2BP2 can promote proliferation, invasion, migration and EMT in vitro. Silencing IGF2BP2 can inhibit proliferation, invasion and migration and EMT in vitro. Similarly, silencing IGF2BP2 can inhibit the proliferation in vivo. The effect of IGF2BP2 was mediated through the PI3K/AKT/EMT signaling pathway. This study will provide a potential marker for the diagnosis and treatment of ESCC.

\section{Declarations}

\section{Authors' contributions}

QDC and XWW were the principal investigator who had managed the research fund, designed project, organized experimental materials; WBS was the major player in performing experiments, drafting of the article; WBS and YHS designed the experimental methods, drafted the manuscript, data collection and 
animal experiments; YJL was involved in clinical sample collection and IHC experiment. All authors read and approved the final manuscript.

\section{Funding}

This research is sponsored by Qingdong Cao's talent-attracting fund (220904094208).

\section{Availability of data and materials}

All data generated or analyzes during this study are included in this published article.

\section{Ethical Approval and Consent to participate}

Ethical approval was obtained from the Ethics Committee of The Fifth Affiliated Hospital, Sun Yat-sen University. Each participant provided written informed consent, and our study conformed to the Declaration of Helsinki.

\section{Consent for publication}

Not applicable.

\section{Competing interests}

The authors declare no conflicts of interest.

\section{Acknowledgements}

Authors are grateful to all subjects for participating in this study. Authors Thank Qing Mai , Ming Zhu Liang, Dan Li for laboratory technical support. Authors are also grateful for comments from reviewers which are valuable for improving manuscript.

\section{References}

1. Smyth EC, Lagergren J, Fitzgerald RC, Lordick F, Shah MA, Lagergren P, Cunningham D. Oesophageal cancer. Nat Rev Dis Primers. 2017Jul 27;3:17048. doi: 10.1038/nrdp.2017.48. Review. PubMed PMID: 28748917; PubMed Central PMCID: PMC6168059.

2. Yang YM, Hong P, Xu WW, He QY, Li B. Advances in targeted therapy for esophageal cancer. Signal Transduct Target Ther. 2020 Oct 7;5(1):229. doi: 10.1038/s41392-020-00323-3. Review. PubMed PMID: 33028804; PubMed Central PMCID: PMC7542465.

3. Fatehi Hassanabad A, Chehade R, Breadner D, Raphael J. Esophageal carcinoma: Towards targeted therapies. Cell Oncol (Dordr). 2020 Apr;43(2):195-209. doi: 10.1007/s13402-019-00488-2. Epub 2019 Dec 17. Review. PubMed PMID: 31848929.

4. Li SM, He LR, Chen JW, Zhou J, Nie RC, Jin XH, Wang X, Fu JH, Wang FW, Xie D. JMJD3 promotes esophageal squamous cell carcinoma pathogenesis through epigenetic regulation of MYC. Signal 
Transduct Target Ther. 2020 Aug 25;5(1):165. doi: 10.1038/s41392-020-00282-9. PubMed PMID: 32843613; PubMed Central PMCID: PMC7447641.

5. Hu X, Peng WX, Zhou H, Jiang J, Zhou X, Huang D, Mo YY, Yang L. IGF2BP2 regulates DANCR by serving as an N6-methyladenosine reader. Cell Death Differ. 2020 Jun;27(6):1782-1794. doi: 10.1038/s41418-019-0461-z. Epub 2019 Dec 5. PubMed PMID: 31804607; PubMed Central PMCID: PMC7244758.

6. Shen C, Xuan B, Yan T, Ma Y, Xu P, Tian X, Zhang X, Cao Y, Ma D, Zhu X, Zhang Y, Fang JY,Chen H, Hong J. m6A-dependent glycolysis enhances colorectal cancer progression. Mol Cancer. $2020 \mathrm{Apr}$ 3;19(1):72. doi: 10.1186/s12943-020-01190-w. PubMed PMID: 32245489; PubMed Central PMCID: PMC7118901.

7. Chatterji P, Rustgi AK. RNA Binding Proteins in Intestinal Epithelial Biology and Colorectal Cancer. Trends Mol Med. 2018 May;24(5):490-506. doi: 10.1016/j.molmed.2018.03.008. Epub 2018 Apr 5. Review. PubMed PMID: 29627433; PubMed Central PMCID: PMC5927824.

8. Chen XY, Zhang J, Zhu JS. The role of m6A RNA methylation in human cancer. Mol Cancer. 2019 May 29; 18(1):103. doi: 10.1186/s12943-019-1033-z. Review. PubMed PMID: 31142332; PubMed Central PMCID: PMC6540575.

9. Yue B, Song C, Yang L, Cui R, Cheng X, Zhang Z, Zhao G. METTL3-mediated N6-methyladenosine modification is critical for epithelial-mesenchymal transition and metastasis of gastric cancer. Mol Cancer. 2019 Oct 13;18(1):142. doi: 10.1186/s12943-019-1065-4. PubMed PMID: 31607270; PubMed Central PMCID: PMC6790244.

10. Wang T, Kong S, Tao M, Ju S. The potential role of RNA N6-methyladenosine in Cancer progression. Mol Cancer. 2020 May 12;19(1):88. doi: 10.1186/s12943-020-01204-7. Review. PubMed PMID: 32398132; PubMed Central PMCID: PMC7216508.

11. Huang $H$, Weng $H$, Sun W, Qin X, Shi H, Wu H, Zhao BS, Mesquita A, Liu C, Yuan CL, Hu YC, Hüttelmaier S, Skibbe JR, Su R, Deng X, Dong L, Sun M, Li C, Nachtergaele S, Wang Y, Hu C, Ferchen K, Greis KD, Jiang X, Wei M, Qu L, Guan JL, He C, Yang J, Chen J. Recognition of RNA N6methyladenosine by IGF2BP proteins enhances mRNA stability and translation. Nat Cell Biol. 2018 Mar;20(3):285-295. doi: 10.1038/s41556-018-0045-z. Epub 2018 Feb 23. PubMed PMID: 29476152; PubMed Central PMCID: PMC5826585.

12. Chatterji P, Rustgi AK. RNA Binding Proteins in Intestinal Epithelial Biology and Colorectal Cancer. Trends Mol Med. 2018 May;24(5):490-506. doi: 10.1016/j.molmed.2018.03.008. Epub 2018 Apr 5. Review. PubMed PMID: 29627433; PubMed Central PMCID: PMC5927824.

13. Tang W, Chen S, Liu J, Liu C, Wang Y, Kang M. Investigation of IGF1, IGF2BP2, and IGFBP3 variants with lymph node status and esophagogastric junction adenocarcinoma risk. J Cell Biochem. 2019 Apr;120(4):5510-5518. doi: 10.1002/jcb.27834. Epub 2018 Oct 18. PubMed PMID: 30335898; PubMed Central PMCID: PMC6587846.

14. Barghash A, Golob-Schwarzl N, Helms V, Haybaeck J, Kessler SM. Elevated expression of the IGF2 mRNA binding protein 2 (IGF2BP2/IMP2) is linked to short survival and metastasis in esophageal 
adenocarcinoma. Oncotarget. 2016 Aug 2;7(31):49743-49750. doi: 10.18632/oncotarget.10439. PubMed PMID: 27391348; PubMed Central PMCID: PMC5226544.

15. Xu X, Yu Y, Zong K, Lv P, Gu Y. Up-regulation of IGF2BP2 by multiple mechanisms in pancreatic cancer promotes cancer proliferation by activating the PI3K/AKT signaling pathway. J Exp Clin Cancer Res. 2019 Dec 18;38(1):497. doi: 10.1186/s13046-019-1470-y. PubMed PMID: 31852504; PubMed Central PMCID: PMC6921559.

16. Cassidy JW, Caldas C, Bruna A. Maintaining Tumor Heterogeneity in Patient-Derived Tumor Xenografts. Cancer Res. 2015 Aug 1;75(15):2963-8. doi: 10.1158/0008-5472.CAN-15-0727. Epub 2015 Jul 15. Review. PubMed PMID: 26180079; PubMed Central PMCID: PMC4539570.

17. Carrl. Lymphatic metastasis. Cancer Metastasis Rev. 1983;2(3):307-17. doi: 10.1007/ BF00048483. Review. PubMed PMID: 6367969.

18. Yang J, Antin P, Berx G, Blanpain C, Brabletz T, Bronner M, Campbell K, Cano A, Casanova J, Christofori G, Dedhar S, Derynck R, Ford HL, Fuxe J, García de Herreros A, Goodall GJ, Hadjantonakis AK, Huang RJY, Kalcheim C, Kalluri R, Kang Y, Khew-Goodall Y, Levine H, Liu J, Longmore GD, Mani SA, Massagué J, Mayor R, McClay D, Mostov KE, Newgreen DF, Nieto MA, Puisieux A, Runyan R, Savagner P, Stanger B, Stemmler MP, Takahashi Y, Takeichi M, Theveneau E, Thiery JP, Thompson EW, Weinberg RA, Williams ED, Xing J, Zhou BP, Sheng G. Guidelines and definitions for research on epithelial-mesenchymal transition. Nat Rev Mol Cell Biol. 2020 Jun;21(6):341-352. doi:

10.1038/s41580-020-0237-9. Epub 2020 Apr 16. Review. PubMed PMID: 32300252; PubMed Central PMCID: PMC7250738.

19. Wei R, Xiao Y, Song Y, Yuan H, Luo J, Xu W. FAT4 regulates the EMT and autophagy in colorectal cancer cells in part via the PI3K-AKT signaling axis. J Exp Clin Cancer Res. 2019 Mar 4;38(1):112. doi: 10.1186/s13046-019-1043-0. PubMed PMID: 30832706; PubMed Central PMCID: PMC6399964.

20. Ma Z, Lou S, Jiang Z. PHLDA2 regulates EMT and autophagy in colorectal cancer via the PI3K/AKT signaling pathway. Aging (Albany NY). 2020 May 8;12(9):7985-8000. doi: 10.18632/aging.103117. Epub 2020 May 8. PubMed PMID: 32385195; PubMed Central PMCID: PMC7244065.

21. Duan S, Huang W, Liu X, Liu X, Chen N, Xu Q, Hu Y, Song W, Zhou J. IMPDH2 promotes colorectal cancer progression through activation of the PI3K/AKT/mTOR and PI3K/AKT/FOXO1 signaling pathways. J Exp Clin Cancer Res. 2018 Dec 5;37(1):304. doi: 10.1186/s13046-018-0980-3. PubMed PMID: 30518405; PubMed Central PMCID: PMC6282329.

22. Hashimoto T, Makino T, Yamasaki M, Tanaka K, Miyazaki Y, Takahashi T,Kurokawa Y, Motoori M, Kimura Y, Nakajima K, Morii E, Mori M, Doki Y. The Pattern of Residual Tumor After Neoadjuvant Chemotherapy for Locally Advanced Esophageal Cancer and Its Clinical Significance. Ann Surg. 2020 May;271(5):875-884. doi: 10.1097/SLA.0000000000003129. PMID: 30829694.

23. Hatogai K, Fujii S, Kitano S, Kojima T, Daiko H, Yoshino T, Ohtsu A, Takiguchi Y, Doi T, Ochiai A. Relationship between the immune microenvironment of different locations in a primary tumour and clinical outcomes of oesophageal squamous cell carcinoma. Br J Cancer. 2020 Feb;122(3):413-420. doi:10.1038/s41416-019-0622-3. Epub 2019 Nov 25. PMID: 31761900; PMCID: PMC7000821. 
24. Zheng L, Zhao Z, Rong L, Xue L, Song Y. RASSF6-TRIM16 axis promotes cell proliferation, migration and invasion in esophageal squamous cell carcinoma. J Genet Genomics. 2019 Oct 20;46(10):477488. doi: 10.1016/j.jgg.2019.10.004. Epub 2019 Nov 14. PMID: 31812473.

25. Zheng S, Shen T, Liu Q, Liu T, Tuerxun A, Zhang Q, Yang L, Han X, Lu X. CXCL6 fuels the growth and metastases of esophageal squamous cell carcinoma cells both in vitro and in vivo through upregulation of PD-L1 via activation of STAT3 pathway. J Cell Physiol. 2020 Dec 23. doi: 10.1002/jcp.30236. Epub ahead of print. PMID: 33368292.

26. Deng X, Jiang Q, Liu Z, Chen W. Clinical Significance of an m6A Reader Gene, IGF2BP2, in Head and Neck Squamous Cell Carcinoma. Front Mol Biosci. 2020;7:68. doi: 10.3389/fmolb.2020.00068. eCollection 2020. PubMed PMID: 32391379; PubMed Central PMCID: PMC7193208.

27. Pu J, Wang J, Qin Z, Wang A, Zhang Y, Wu X, Wu Y, Li W, Xu Z, Lu Y, Tang Q, Wei H. IGF2BP2 Promotes Liver Cancer Growth Through an m6A-FEN1-Dependent Mechanism. Front Oncol. 2020;10:578816. doi: 10.3389/fonc.2020.578816. eCollection 2020. PubMed PMID: 33224879; PubMed Central PMCID: PMC7667992.

28. Hu G, Jiang Q, Liu L, Peng H, Wang Y, Li S, Tang Y, Yu J, Yang J, Liu Z. Integrated Analysis of RNABinding Proteins Associated With the Prognosis and Immunosuppression in Squamous Cell Carcinoma of Head and Neck. Front Genet. 2020;11:571403. doi: 10.3389/fgene.2020.571403. eCollection 2020. PubMed PMID: 33505420; PubMed Central PMCID: PMC7831273.

29. Yang Y, Liu X, Cheng L, Li L, Wei Z, Wang Z, Han G, Wan X, Wang Z, Zhang J, Chen C. Tumor Suppressor microRNA-138 Suppresses Low-Grade Glioma Development and Metastasis via Regulating IGF2BP2. Onco Targets Ther. 2020;13:2247-2260. doi: 10.2147/OTT.S232795. eCollection 2020. PubMed PMID: 32214825; PubMed Central PMCID: PMC7082711.

30. McMullen ER, Gonzalez ME, Skala SL, Tran M, Thomas D, Djomehri SI, Burman B, Kidwell KM, Kleer CG. CCN6 regulates IGF2BP2 and HMGA2 signaling in metaplastic carcinomas of the breast. Breast Cancer Res Treat. 2018 Dec;172(3):577-586. doi: 10.1007/s10549-018-4960-2. Epub 2018 Sep 15. PubMed PMID: 30220054; PubMed Central PMCID: PMC6424355.

31. Bakir B, Chiarella AM, Pitarresi JR, Rustgi AK. EMT, MET, Plasticity, and Tumor Metastasis. Trends Cell Biol. 2020 Oct;30(10):764-776. doi: 10.1016/j.tcb.2020.07.003. Epub 2020 Aug 13. Review. PubMed PMID: 32800658; PubMed Central PMCID: PMC7647095.

32. Georgakopoulos-Soares I, Chartoumpekis DV, Kyriazopoulou V, Zaravinos A. EMT Factors and Metabolic Pathways in Cancer. Front Oncol. 2020;10:499. doi: 10.3389/fonc.2020.00499. eCollection 2020. Review. PubMed PMID: 32318352; PubMed Central PMCID: PMC7154126.

33. Yuan K, Xie K, Lan T, Xu L, Chen X, Li X, Liao M, Li J, Huang J, Zeng Y, Wu H. TXNDC12 promotes EMT and metastasis of hepatocellular carcinoma cells via activation of $\beta$-catenin. Cell Death Differ. 2020 Apr; 27(4): 1355-1368. doi: 10.1038/s41418-019-0421-7. Epub 2019 Sep 30. PubMed PMID: 31570854; PubMed Central PMCID: PMC7206186.

34. Sommariva M, Gagliano N. E-Cadherin in Pancreatic Ductal Adenocarcinoma: A Multifaceted Actor during EMT. Cells. 2020 Apr 22;9(4). doi: 10.3390/cells9041040. Review. PubMed PMID: 32331358; 
PubMed Central PMCID: PMC7226001.

35. Carmichael CL, Wang J, Nguyen T, Kolawole O, Benyoucef A, De Mazière C, Milne AR, Samuel S, Gillinder K, Hediyeh-Zadeh S, Vo ANQ, Huang Y, Knezevic K, McInnes WRL, Shields BJ, Mitchell H, Ritchie ME, Lammens T, Lintermans B, Van Vlierberghe P, Wong NC, Haigh K, Thoms JAl, Toulmin E, Curtis DJ, Oxley EP, Dickins RA, Beck D, Perkins A, McCormack MP, Davis MJ, Berx G, Zuber J, Pimanda JE, Kile BT, Goossens S, Haigh JJ. The EMT modulator SNAI1 contributes to AML pathogenesis via its interaction with LSD1. Blood. 2020 Aug 20;136(8):957-973. doi: 10.1182/blood.2019002548. PubMed PMID: 32369597; PubMed Central PMCID: PMC7441169.

36. Shao Q, Zhang Z, Cao R, Zang H, Pei W, Sun T. CPA4 Promotes EMT in Pancreatic Cancer via Stimulating PI3K-AKT-mTOR Signaling. Onco Targets Ther. 2020;13:8567-8580. doi: 10.2147/OTT.S257057. eCollection 2020. PubMed PMID: 32922037; PubMed Central PMCID: PMC7457871.

37. Wang H, Zhao Y, Cao L, Zhang J, Wang Y, Xu M. Metastasis suppressor protein 1 regulated by PTEN suppresses invasion, migration, and EMT of gastric carcinoma by inactivating PI3K/AKT signaling. J Cell Biochem. 2019 Mar;120(3):3447-3454. doi: 10.1002/jcb.27618. Epub 2018 Sep 23. PubMed PMID: 30246429.

38. Xu X, Yu Y, Zong K, Lv P, Gu Y. Up-regulation of IGF2BP2 by multiple mechanisms in pancreatic cancer promotes cancer proliferation by activating the PI3K/Akt signaling pathway. J Exp Clin Cancer Res. 2019 Dec 18;38(1):497. doi: 10.1186/s13046-019-1470-y. PubMed PMID: 31852504; PubMed Central PMCID: PMC6921559.

39. Shao Q, Zhang Z, Cao R, Zang H, Pei W, Sun T. CPA4 Promotes EMT in Pancreatic Cancer via Stimulating PI3K-AKT-mTOR Signaling. Onco Targets Ther. 2020;13:8567-8580. doi: 10.2147/OTT.S257057. eCollection 2020. PubMed PMID: 32922037; PubMed Central PMCID: PMC7457871.

40. Mu Q, Wang L, Yu F, Gao H, Lei T, Li P, Liu P, Zheng X, Hu X, Chen Y, Jiang Z, Sayari AJ, Shen J, Huang $\mathrm{H}$. Imp2 regulates GBM progression by activating IGF2/PI3K/Akt pathway. Cancer Biol Ther. 2015;16(4):623-33. doi: 10.1080/15384047.2015.1019185. Epub 2015 Feb 26. PubMed PMID: 25719943; PubMed Central PMCID: PMC4622833.

\section{Figures}


a
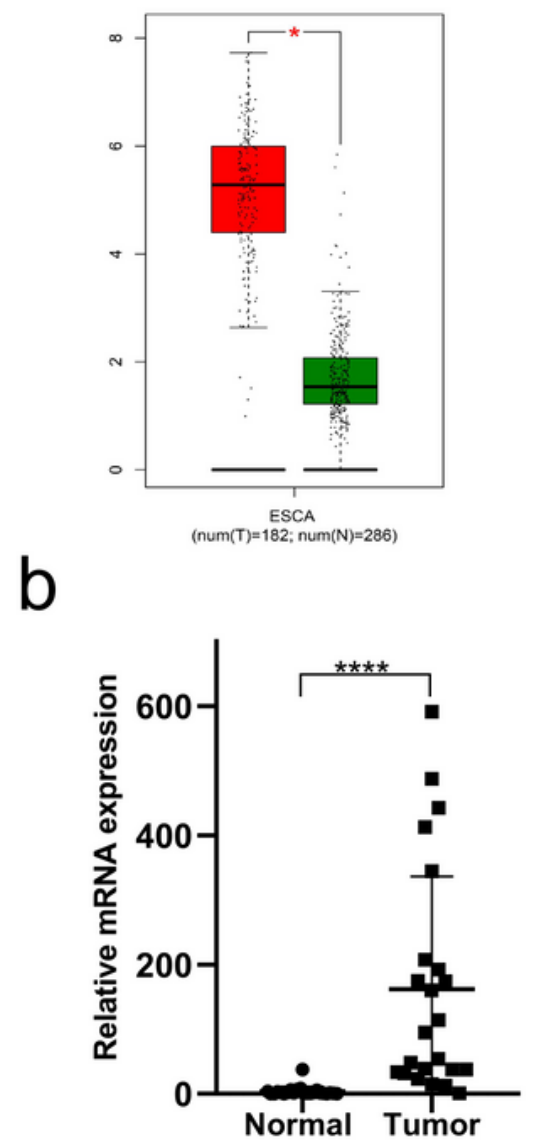

d

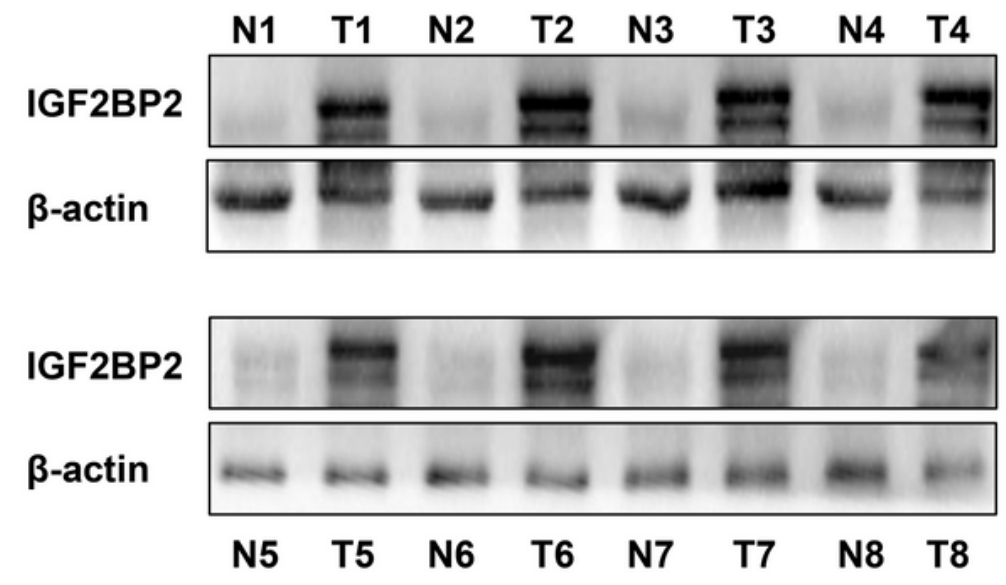

C
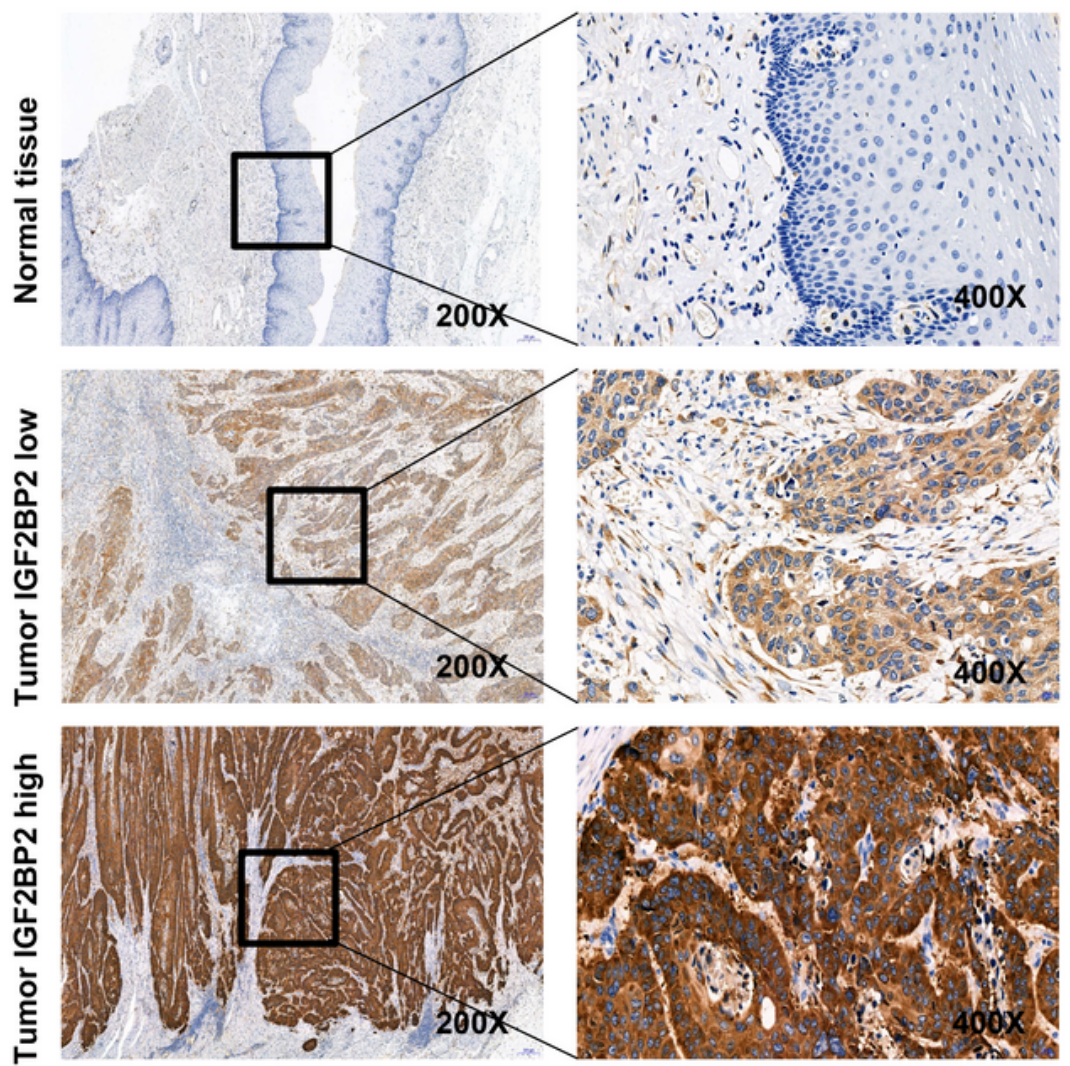

e

\section{Figure 1}

IGF2BP2 was overexpressed in esophageal cancer a. IGF2BP2 mRNA levels in 182 ESCC tissues and 288 normal tissues in the GEPIA database. b. IGF2BP2 mRNA levels in 23 ESCC tissues and paired normal tissues. c. Representative immunohistochemistry images; 200x magnification, scale bar: $50 \mu \mathrm{m} ; 400 \times$ magnification, scale bar: $20 \mu \mathrm{m}$. d. Western blotting showing the IGF2BP2 protein expression levels in 
ESCC tissues and normal tissues, with $\beta$-actin protein expression levels serving as the internal reference control. The quantification of the three independent repeated experiments is shown $(n=15, p<0.0001)$.

a

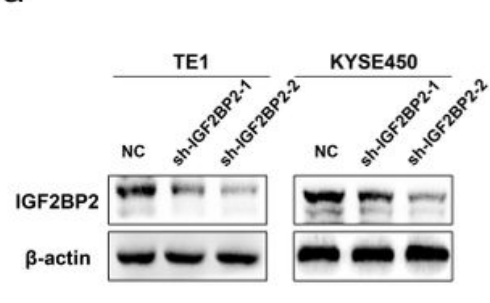

b

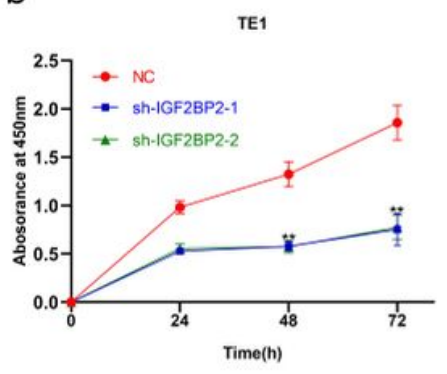

C

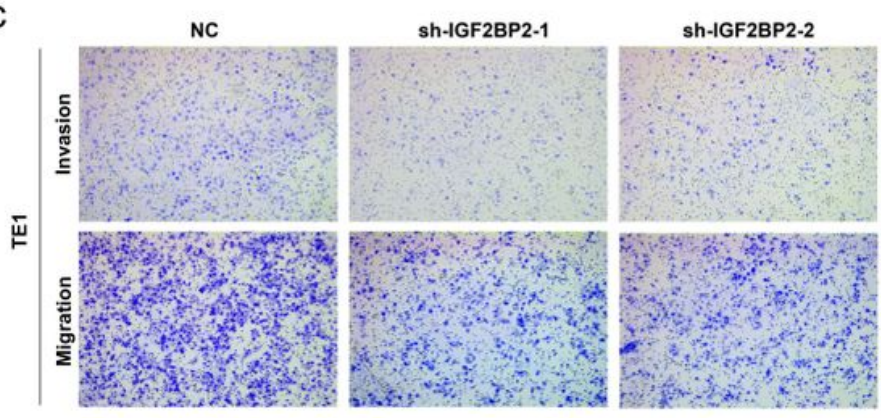

KYSE450
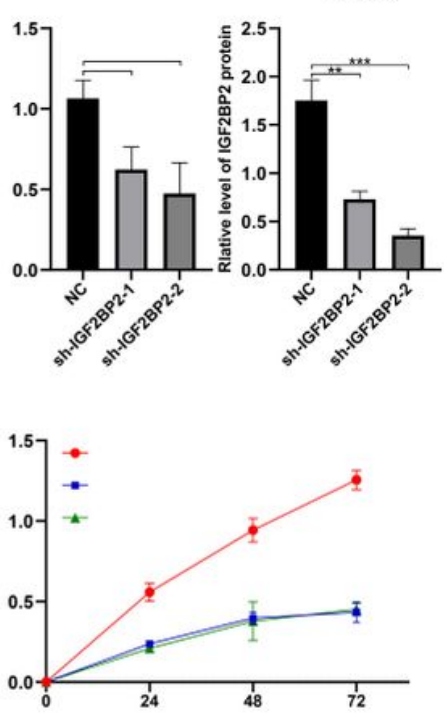

d

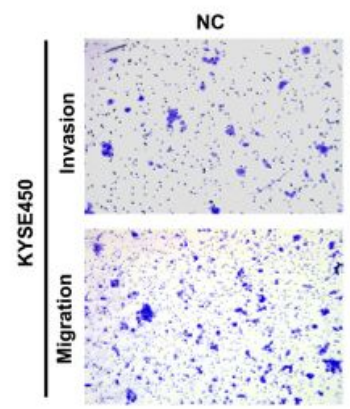

sh-IGF2BP2-1

sh-IGF2BP2-2
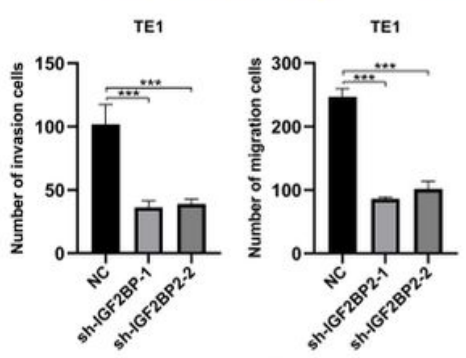

Sh-IGF2BP2-1
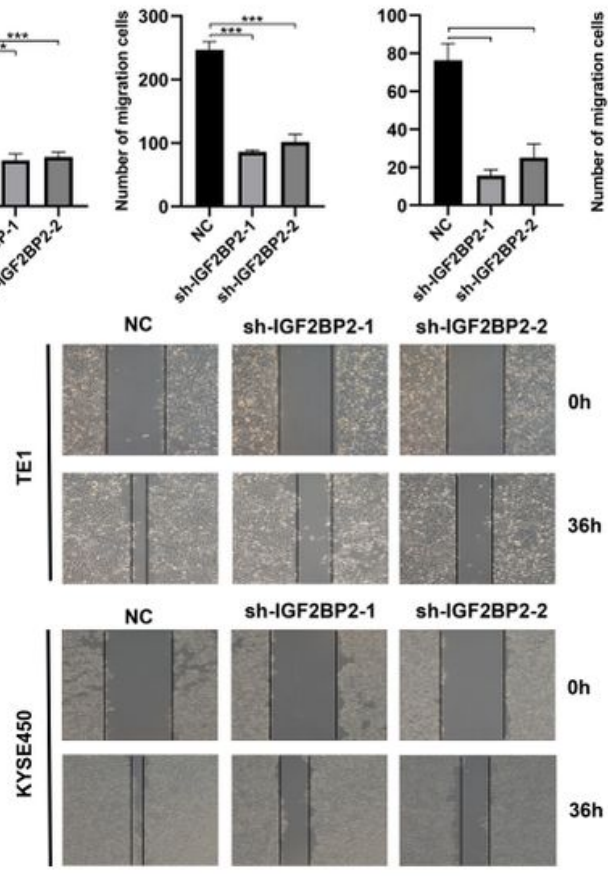

sh-IGF2BP2-1

sh-IGF2BP2-2

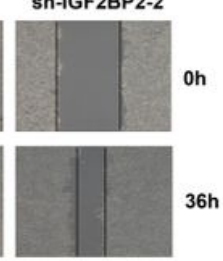

\section{Figure 2}

Downregulation of IGF2BP2 expression suppressed the proliferation, migration and invasion of ESCC cells. a. IGF2BP2 protein levels in the TE1 and KYSE450 cell lines were observed after transfected with shIGF2BP2-1, shIGF2BP2-2 and normal control. b. CCK-8 assays were performed to determine cell growth after IGF2BP2 was knocked down in TE1 and KYSE 450 cells. c. Knockdown of IGF2BP2 decreased the migration and invasion abilities of TE1 and KYSE450 cells. The data are shown as the mean \pm S.D. *P< $0.05,{ }^{*} \mathrm{P}<0.01,{ }^{\star \star *} \mathrm{P}<0.001,{ }^{\star * \star *} \mathrm{P}<0.0001$. Wound healing assays showed that downregulation of IGF2BP2 expression reduced the migration ability of TE1 and KYSE450 cells in vitro (magnification: 10x, scale bar: $100 \mu \mathrm{m})$. 
a

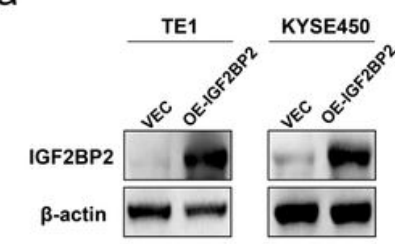

b

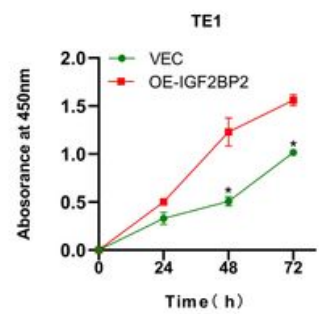

C

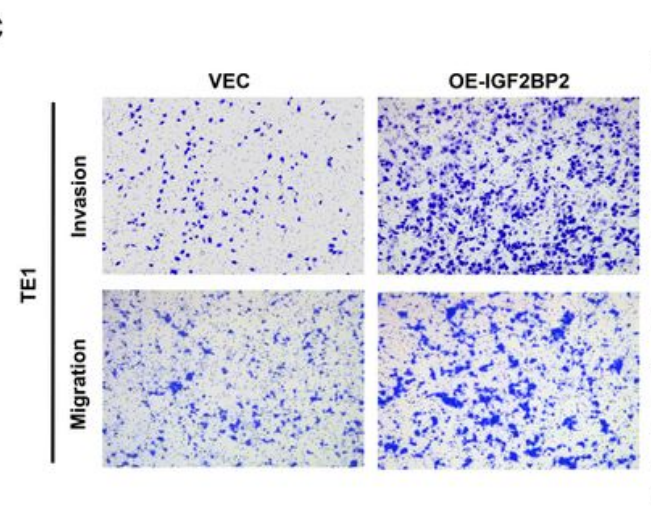

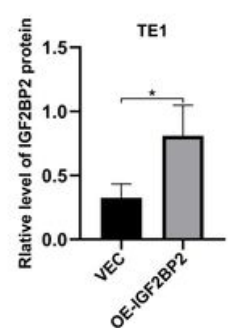
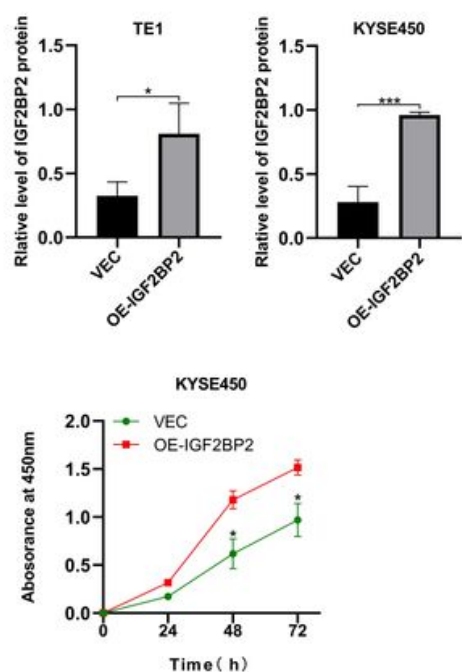

TE1

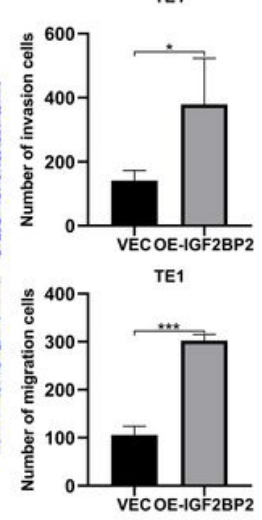

VEC
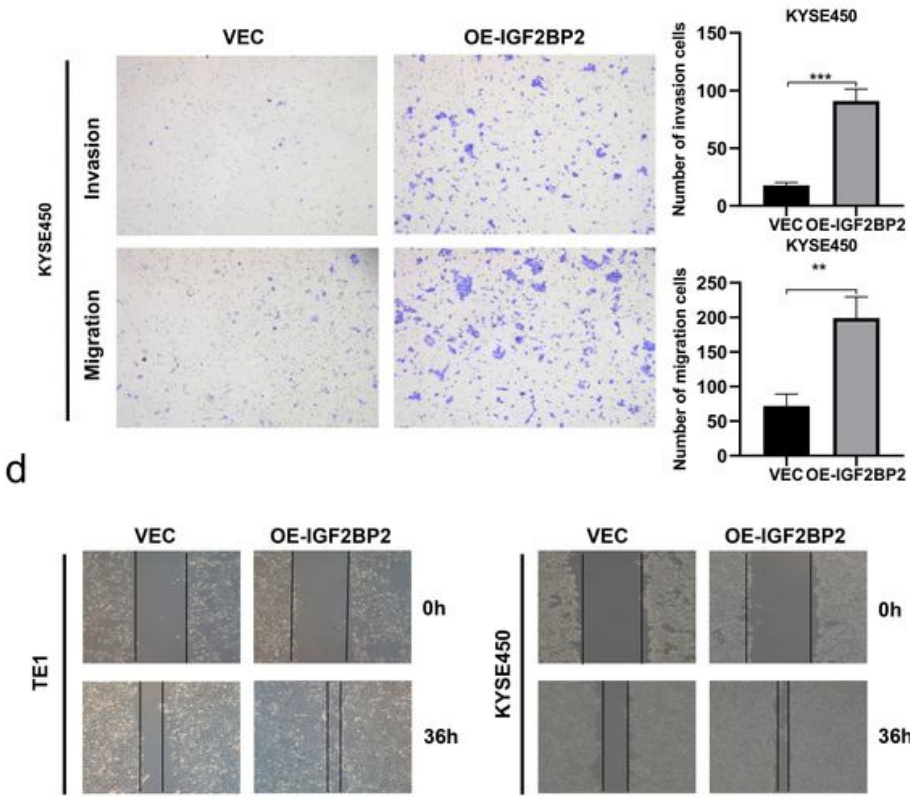

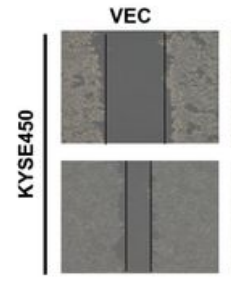

OE-IGF2BP2

\section{Figure 3}

Overexpression of IGF2BP2 promoted proliferation, migration, and invasion of ESCC a. IGF2BP2 protein levels in cells of transfected with the IGF2BP2 overexpression plasmid. b. CCK-8 assays were performed to determine cell growth after IGF2BP2 was overexpressed in TE1 and KYSE 450 cells. c. Overexpression of IGF2BP2 increased the migration and invasion abilities of TE1 and KYSE450 cells. The data are shown as the mean \pm S.D. ${ }^{*} P<0.05,{ }^{*} P<0.01,{ }^{*} * \mathrm{P}<0.001$. d. Wound healing assay in TE1 and KYSE450 cells overexpression IGF2BP2, 36 hours after cells were wounded (magnification: 10x, scale bar: $100 \mu \mathrm{m}$ ). 


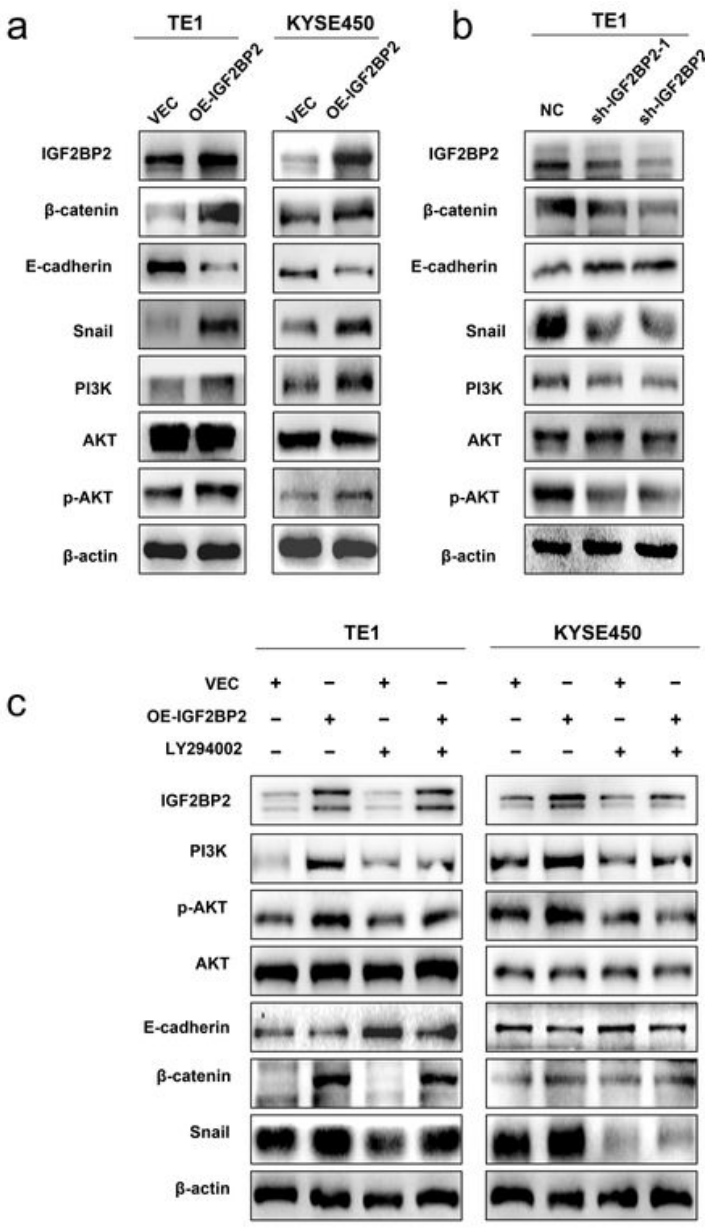

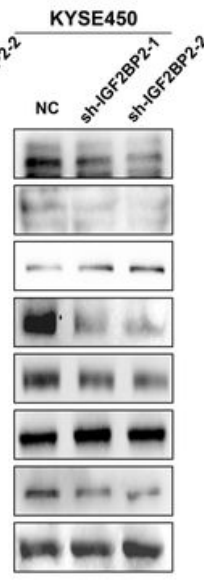
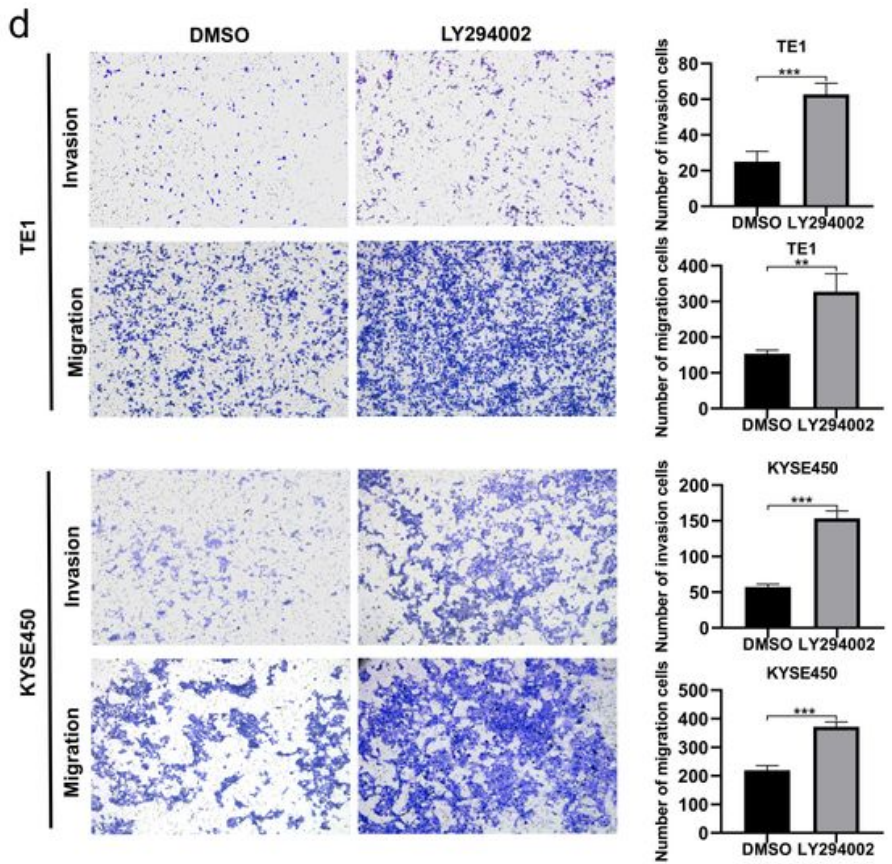

e
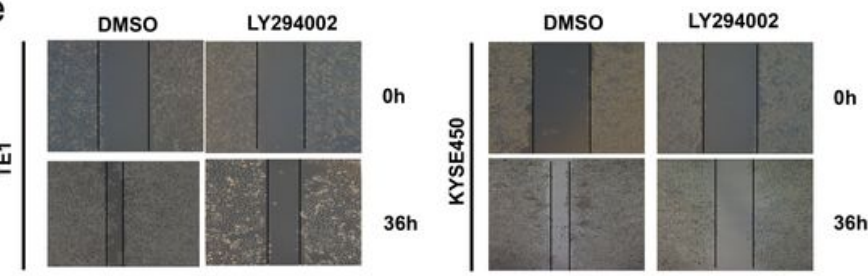

\section{Figure 4}

IGF2BP2 regulated the epithelial-mesenchymal transition (EMT) and PI3K/AKT signaling pathway activation in ESCC cell lines a. Western blotting analysis of EMT markers and their levels in IGF2BP2overexpressing TE1 and KYSE450 cells. b. Western blotting analysis of EMT markers and their levels in TE1 and KYSE450 cells in which IGF2BP2 expression was downregulated. c. Western blotting analysis of EMT markers and PI3K/AKT-related proteins (PI3K, AKT, p-AKT). Overexpression of IGF2BP2 in TE1 and KYSE450 cells treated with $50 \mu \mathrm{m} / \mathrm{ml}$ LY294002 for 24 hours. $d$. Transwell assay with IGF2BP2overexpressing TE1 and KYSE450 cells. The cells were treated with DMSO and $50 \mu \mathrm{m} / \mathrm{ml} \mathrm{LY294002} \mathrm{for}$ 24 hours. The wound healing assay performed after the IGF2PB2-overexpressing TE1 and KYSE450 cells were treated with DMSO and the PI3K inhibitor LY294002, respectively (magnification: 10x, scale bar: 100 $\mu \mathrm{m})$. 


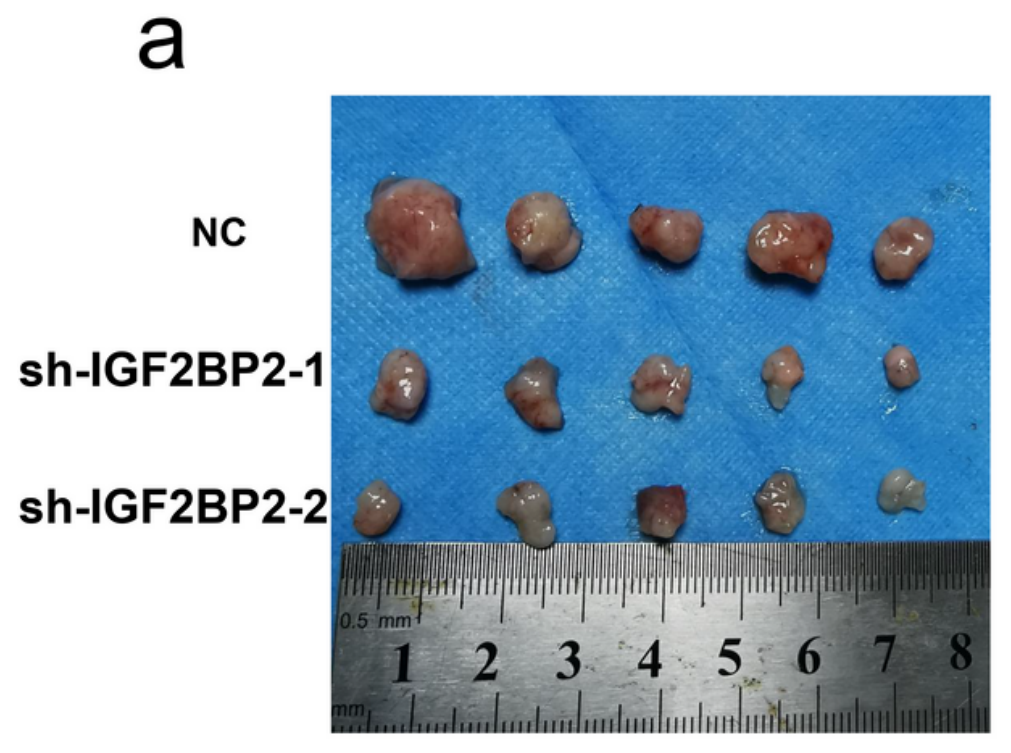

C

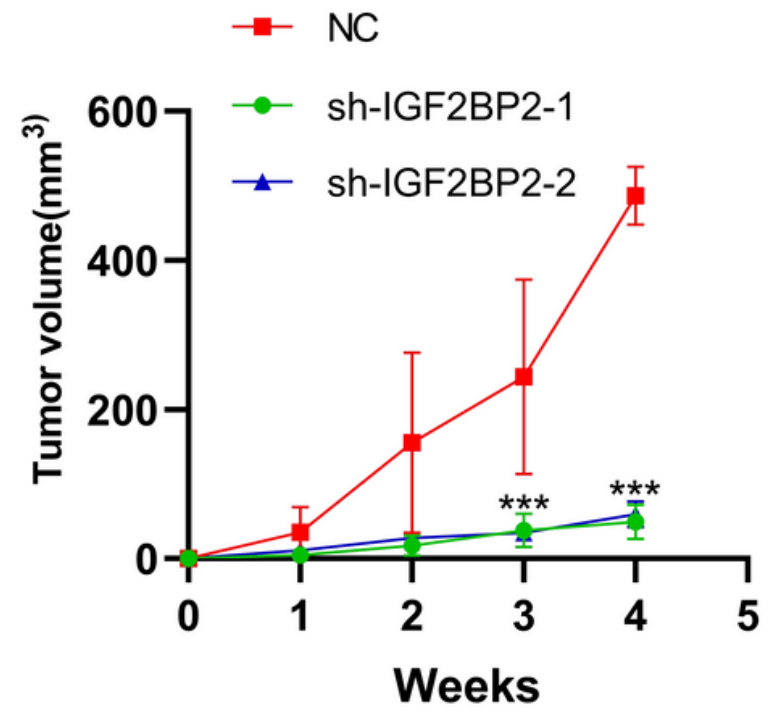

b

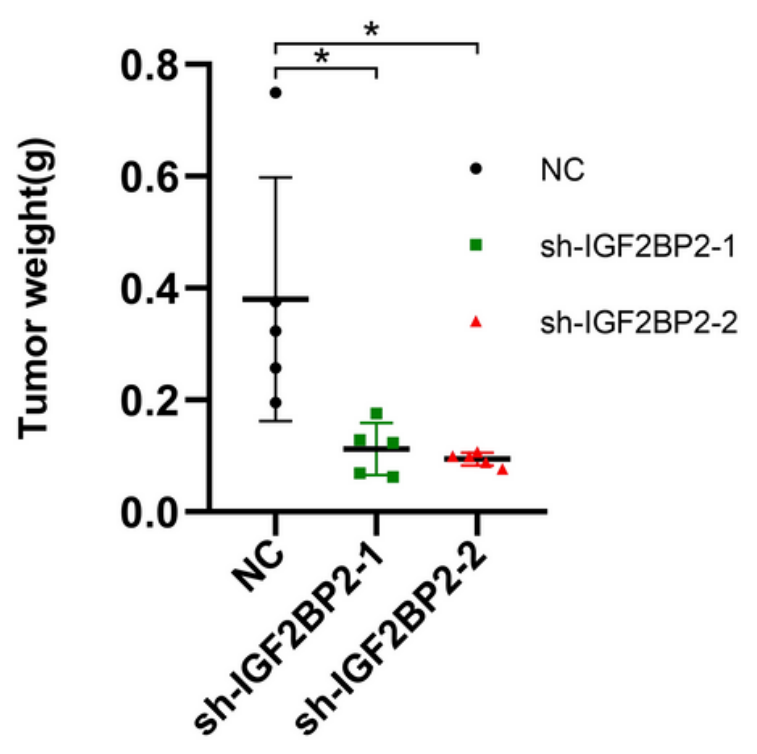

Figure 5

Downregulation of IGF2BP2 suppressed tumor growth in vivo. a. The tumor size of the IGF2BP2knockdown mouse model was measured after the mice were killed. $b$. The tumor weight of the IGF2BP2knockdown mouse model was measured after the mice were killed. c. The tumor volume was measured every week. The data are shown as the mean \pm S.D.

\section{Supplementary Files}

This is a list of supplementary files associated with this preprint. Click to download.

- renamed031ce.doc 